\title{
MÓVEIS RA E UMA DECISÃO COMERCIAL ESTRATÉGICA
}

\section{Rosimeri Machado}

Universidade de Caxias do Sul

\section{Sylvia Maria Azevedo Roesch}

Universidade de Caxias do Sul

\section{Pelayo Munhoz Olea}

Universidade de Caxias do Sul

\section{Fernando Luís Bertolla}

Universidade de Caxias do Sul

\section{Maurício Caetano Nedeff}

Universidade de Caxias do Sul

\section{Introdução}

A Móveis RA Ltda. ${ }^{1}$ é uma empresa de médio porte constituída em 1981, localizada na Serra Gaúcha, marcada pelo sério trabalho desenvolvido pelos seus sócios e funcionários, alguns com mais de 10 anos de empresa. Os sócios da empresa são a terceira geração da família a se estabelecer no ramo moveleiro.

\footnotetext{
${ }^{1}$ A empresa e os personagens do caso aparecem com nomes fictícios, embora a situação relatada seja real. Os nomes verdadeiros foram omitidos por razões de confidencialidade.
}

\section{CFGV-EAESP/RAE 2011}

Todos os direitos reservados. Permitidas a citação e a reprodução parcial ou total, desde que identificada a fonte. Em caso de dúvidas, consulte a Redação: gvcasos.redacao@fgv.br; (11) 3799-3717 
O próspero crescimento da Móveis RA projetou-a para o almejado mercado de exportação, mudando o seu foco, no ano de 2000, para atuação dedicada ao mercado externo. Porém, a partir de meados de 2005, o comércio internacional passou a sofrer oscilação em função da redução da taxa cambial utilizada até então para conversão da moeda real em dólar. Essa situação preocupante foi se acentuando em 2006 e 2007, também com a concorrência chinesa, de modo que a empresa precisou rever seus custos e preços de venda. Os sócios da empresa, Sr. Osmar e Sr. Salvador, tinham que tomar uma importante decisão: manter a empresa voltada totalmente ao mercado externo, com novas estratégias comerciais, ou ampliar sua participação no mercado interno, evitando os desgastes com instabilidade cambial e concorrência chinesa?

\section{Histórico}

A empresa aqui abordada foi fundada em 1981, na Serra Gaúcha, com a razão social Madeiras RA Ltda., sob propriedade dos Srs. Salvador e Osmar Rac, filho de Salvador. Em 1992, transferiu-se para o distrito industrial de sua cidade, passando a utilizar uma área de $2.600 \mathrm{~m}^{2}$ e a denominar-se Móveis RA Ltda., atual razão social da empresa, com um novo enfoque de mercado: produção seriada de móveis.

Em 1993, com a ampliação dos negócios, iniciou-se a exportação de móveis de madeira maciça para os Estados Unidos.

Atualmente, a empresa exporta $100 \%$ do que produz, sendo seu principal mercado de exportação os Estado Unidos, com uma participação de 70\%, porém seus produtos encontram-se em outros países, como Áustria, Holanda, Suíça, Alemanha, França e Inglaterra.

Os móveis produzidos buscam atender os mais variados segmentos: móveis para dormitórios, cozinhas, sala e escritório.

As novidades e tendências do mercado são avaliadas por diversos meios, entre eles: pela percepção das necessidades dos clientes que visitam a empresa periodicamente, assimilação de novas ideias que são obtidas durante frequentes viagens a feiras internacionais de móveis e pelo convívio com designers e profissionais do mercado que vêm até a empresa para participar da elaboração de protótipos e detalhes de novos projetos. 
$\mathrm{Na}$ área de desenvolvimento de produtos, a empresa conta com uma equipe especializada, além de apoiar a formação de novos profissionais. A linha de produtos é desenvolvida para o período de validade de um catálogo, ou seja, para uma estação do ano específica, devendo, para a temporada seguinte, ser criados outros produtos para que o consumidor tenha novas opções de escolha no catálogo de móveis.

Atualmente, a Móveis RA conta com 310 funcionários e uma área instalada de $13.600 \mathrm{~m}^{2}$.

\section{O contexto competitivo do setor moveleiro}

A estrutura produtiva da cadeia moveleira mundial é, em sua maioria, composta por pequenas e médias empresas. Em relação ao comércio mundial, o setor era dominado pelos países desenvolvidos, como Itália, Alemanha e Estados Unidos, que, até o início da década de 1990, respondiam por mais de $40 \%$ das exportações mundiais. Posteriormente, outros países inseriram-se nesse contexto: China, Taiwan, Malásia, México e Indonésia, entre outros, inserindo novos designs, novas matérias-primas, novas tecnologias, especialização de produção e estratégias de distribuição e comércio (FIESP, 2009).

Os 20 principais países exportadores, em 2006, representavam $84,5 \%$ do total mundial, sendo que o Brasil aparecia na $22^{a}$ posição, com participação de $1,2 \%$ no mercado mundial de exportações de móveis e crescimento superior à média dos 20 principais exportadores, que foi de $70 \%$, enquanto o Brasil cresceu 117\%. Conforme mostra o Anexo 1, a China lidera as exportações de móveis com 14,9\% de participação de mercado mundial e um crescimento de $258 \%$ no período de 2001 a 2006, seguida pela Itália, com 12,1\% do mercado e um crescimento menor, de 35\% (FIESP, 2009).

Nas importações, os Estados Unidos concentram 31,3\% (Anexo 2) do total mundial, sendo que, entre 2001 a 2006, as importações do país cresceram 79,5\%, sendo o maior mercado consumidor. Outros países apresentaram grande crescimento nas importações mundiais: República da Coreia (372,7\%), Austrália (191,80\%), República Tcheca (177,3\%) e Espanha (171,3\%) (FIESP, 2009).

Segundo o relatório setorial da indústria de móveis no brasil (IEMI, 2009), os principais países de origem das exportações dos Estados Unidos em 2007 foram: China, com uma participação de 54,4\%, seguida por Canadá, com 13,5\%, e o Brasil ocupa a $13^{\mathrm{a}}$ posição, com quedas em sua participação, nos anos de 2005, 2006 e 2007, de 36,8\%. 
As exportações de móveis no Brasil em 2007 foram de US\$ 869,3 milhões, decrescendo 4,72\% em comparação ao ano anterior, quando foram de US\$ 912,3 milhões. O principal destino das exportações brasileiras foram os Estados Unidos (Anexo 3), com 25,11\%. Estados Unidos e França apresentam taxas de crescimento menores, $72 \%$ e 30\% respectivamente, sendo que, de 2006 a 2007, a importação de produtos brasileiros por esses países decresceu (os Estados Unidos, em 2006, importaram do Brasil US\$ 265 milhões e, em 2007, o montante de US\$ 218 milhões) (FIESP, 2009).

Entre os 20 principais compradores de móveis brasileiros, nove países são da América Latina e responderam por $21,4 \%$ de todas as vendas brasileiras desse produto em 2007. Destaca-se o desempenho de vendas para o Peru, com crescimento de 1.280\%, Angola, de 3.553,8\%, e Espanha, de $1.389,1 \%$ (FIESP, 2009).

Em 2006, a indústria moveleira no Brasil produziu R \$ 10,21 bilhões, sendo que $80 \%$ desse valor foi para consumo interno, o qual sustentou a indústria no país, conforme mostrado no Anexo 4 . Os estados com maiores índices de consumo são: São Paulo, com 30,2\% do total de gasto das famílias brasileiras, seguido pelo Rio de Janeiro, com 11\%, e Minas Gerais, com 8,8\%, e juntos respondem por mais de 50\% do consumo total no Brasil de móveis (FIESP, 2009).

Segundo dados do relatório setorial da indústria de móveis no brasil (IEMI, 2009), o consumo interno entre 2004 e 2007 apresentou crescimento constante (Anexo 5), ao contrário das exportações, que vêm apresentando oscilações.

No Rio Grande do Sul, conforme dados do relatório setorial da indústria de móveis no brasil (IEMI, 2009), o Reino Unido (13,9\%), seguido pelos Estados Unidos (10,6\%), foi o principal destino das exportações em 2007 das empresas moveleiras; sendo que, em 2006, os Estados Unidos ocupavam a liderança, com participação de $16,4 \%$.

\section{$O$ contexto do problema}

Este caso é baseado em relatos do diretor da empresa, Sr. Osmar, e do Gerente Comercial, Sr. Epitáfio Mor, que trabalha na empresa há mais de 12 anos. O Sr. Osmar é formado em Engenharia da Produção e tem vasta experiência moveleira; o Sr. Epitáfio é tecnólogo em Produção Moveleira e, por estar há um bom tempo na empresa, conhece amplamente os processos e o mercado de móveis. 
Os anos de 2001 a 2005 foram interessantes para a empresa, sendo que a elevação de 2,46, em maio de 2002, chegando a 3,61, em março de 2003, na taxa cambial de cotação do dólar norteamericano (moeda utilizada para a comercialização da empresa), no final de 2002 até os primeiros meses de 2003, contribuiu para a elevação do faturamento. Nesse período, houve eleições presidenciais, ocorridas em outubro de 2002, quando disputavam a presidência Luiz Inácio Lula da Silva (PT) e José Serra (PSDB); como Lula tinha grande possibilidade de vencer a eleição, o mercado ficou receoso, o que elevou a taxa cambial do dólar.

No início de 2008, o Sr. Osmar e o Sr. Epitáfio realizaram uma reunião com os demais supervisores e gerentes da empresa para avaliar, principalmente, a evolução do percentual de crescimento do faturamento da empresa do período de 2001 até o final do período contábil de 2007, conforme Anexo 6. Em 2002, a empresa apresentou um crescimento de 19,22\% no valor do faturamento em relação ao ano de 2001, no ano seguinte teve novo crescimento de 18,77\%, já em 2004, apresentou um declínio de 5,03\%, o qual foi recuperado no ano seguinte, com um crescimento de $15,10 \%$, porém os anos seguintes seriam a maior preocupação da empresa.

Não obstante essa análise, buscaram também informações no mercado, verificando a evolução da taxa cambial durante o período analisado, e confrontando-as com as taxas cambiais (real x dólar), praticadas nas vendas da empresa no período de 2002 a 2007, conforme Anexo 7, permitindo elaborar um gráfico, reproduzido no Anexo 8, que demonstra claramente a queda de faturamento com o passar dos últimos dois anos.

Diante dessa circunstância, Osmar e Epitáfio estavam diante de uma importante tomada de decisão para o futuro da Móveis RA: voltar-se estrategicamente para o mercado interno ou definir novas estratégias e continuar focada $100 \%$ no mercado externo?

Durante a reunião, além de tratar da taxa cambial que estava em declínio, foram abordados outros temas relevantes, como:

- A crise que abatia os Estados Unidos, que, até então, era o principal mercado consumidor dos móveis da empresa;

- A queda da taxa do dólar forçou o aumento das matérias-primas brasileiras, elevando assim os custos de produção da empresa e consequentemente impactando no preço de venda dos móveis; 
- Forte concorrência externa, principalmente chinesa, que apresentava móveis a um custo menor do que o brasileiro;

- O crédito dos impostos para as empresas predominantemente exportadoras oferecido pelo governo, de maneira muito morosa, o que prejudicava o fluxo de caixa da empresa;

- O mercado exterior não estava receptivo a aumento de preços, o que impossibilitava a empresa de realizar os ajustes necessários na formação do preço de venda;

- Voltar-se ao mercado interno carecia de alguns investimentos, além de acarretar a remodelagem dos designs dos móveis até então comercializados;

- Mercado consumidor nacional aquecido.

\section{Tomada de decisão}

Mediante esse cenário apresentado, os dirigentes, Sr. Osmar e Sr. Epitáfio, tinham que tomar alguma decisão:

- Para retomar o crescimento do faturamento (e não estar totalmente suscetível às crises mundiais e à economia com taxas cambiais flutuantes e inseguras, bem como à concorrência chinesa), iniciar uma nova linha de produtos no mercado interno, com a possibilidade de criar parcerias por meio de desenvolvimento de canais nacionais de distribuição, concessão de franquias ou até mesmo a criação de filiais, com o objetivo de comercializar os produtos diretamente ao cliente final. Considerando que esse reposicionamento também exige um considerável investimento em marketing, para que a empresa e seus produtos se tornem conhecidos pelos clientes potenciais das regiões a serem exploradas.

- Elaboração de uma nova estratégia para o mercado externo, desenvolvendo novos clientes com produtos diferenciados de maior valor agregado.

- Com a tendência de o dólar se estabilizar ou cair ainda mais, comercializar em outra moeda, por exemplo, o euro.

Esses tópicos foram apresentados em reunião com os envolvidos na gestão da Móveis RA, para que chegassem a uma conclusão conjunta, uma vez que a decisão deveria ser implantada no mesmo ano, ou seja, 2008. 


\section{Anexo 1}

Principais países exportadores de móveis em US\$ no período de 2001 a 2006*

\begin{tabular}{|c|c|c|c|c|}
\hline & Países & 2006 (US\$) & $\begin{array}{l}\text { Market Share - } \\
2006\end{array}$ & $\begin{array}{c}\% \text { Crescimento } \\
2001 / 2006\end{array}$ \\
\hline 1 & China & 11.762 .470 .665 & $14,9 \%$ & $258 \%$ \\
\hline 2 & Itália & 9.567 .836 .670 & $12,1 \%$ & $35 \%$ \\
\hline 3 & Alemanha & 6.735 .862 .000 & $8,5 \%$ & $82 \%$ \\
\hline 4 & Polônia & 5.509 .595 .330 & $7,0 \%$ & $142 \%$ \\
\hline 5 & Canadá & 4.498 .604 .717 & $5,7 \%$ & $31 \%$ \\
\hline 6 & \begin{tabular}{|l|} 
México \\
\end{tabular} & 4.124 .737 .848 & $5,2 \%$ & $43 \%$ \\
\hline 7 & EUA & 4.035 .478 .145 & $5,1 \%$ & $20 \%$ \\
\hline 8 & França & 2.243 .628 .722 & $2,8 \%$ & $42 \%$ \\
\hline 9 & Dinamarca & 2.055 .014 .547 & $2,6 \%$ & $31 \%$ \\
\hline 10 & Malásia & 1.939 .746 .897 & $2,5 \%$ & $68 \%$ \\
\hline 11 & Indonésia & 1.794 .449 .930 & $2,3 \%$ & $30 \%$ \\
\hline 12 & Vietnä & 1.675 .967 .010 & $2,1 \%$ & $539 \%$ \\
\hline 13 & República Tcheca & 1.607 .194 .049 & $2,0 \%$ & $99 \%$ \\
\hline 14 & Áustria & 1.492 .124 .850 & $1,9 \%$ & $45 \%$ \\
\hline 15 & Bélgica & 1.434 .332 .798 & $1,8 \%$ & $14 \%$ \\
\hline 16 & Suécia & 1.405 .077 .331 & $1,8 \%$ & $66 \%$ \\
\hline 17 & Espanha & 1.369 .565 .644 & $1,7 \%$ & $23 \%$ \\
\hline 18 & Romênia & 1.158 .176 .023 & $1,5 \%$ & $138 \%$ \\
\hline 19 & Reino Unido & 1.153 .022 .140 & $1,5 \%$ & $27 \%$ \\
\hline 20 & Tailândia & 1.097 .662 .357 & $1,4 \%$ & $50 \%$ \\
\hline & Total da Amostra & 66.660 .547 .673 & $84,5 \%$ & $70 \%$ \\
\hline 22 & Brasil & 912.389 .063 & $1.2 \%$ & $117 \%$ \\
\hline & & & & \\
\hline 137 & Total Geral & 78.879 .205 .951 & $100,0 \%$ & $74 \%$ \\
\hline
\end{tabular}

Fonte: COMTRADE/ONU; elaboração DECOMTEC/FIESP.

* Dados dos produtos “móveis" classificados nas seguintes nomenclaturas do Mercosul: 940140, 940150, 940161, 940169, 940180, 940190, 940330, 940340, 940350, 940360, 940370, 940380, 940390. 
Anexo 2

Principais países importadores de móveis (em US\$) em 2006; crescimento das importações de 2001 a 2006*

\begin{tabular}{|c|c|c|c|c|}
\hline & Paises & 2006 (US\$) & $\begin{array}{c}\text { Market Share - } \\
2006 \\
\end{array}$ & $\begin{array}{c}\text { \% Crescimento } \\
2001 / 2006 \\
\end{array}$ \\
\hline 1 & EUA & 26.327 .703 .287 & $31,3 \%$ & $79,5 \%$ \\
\hline 2 & Alemanha & 8.261 .087 .000 & $9,8 \%$ & $53,5 \%$ \\
\hline 3 & Reino Unido & 6.132 .543 .706 & $7,3 \%$ & $113,1 \%$ \\
\hline 4 & França & 5.341 .229 .575 & $6,3 \%$ & $88,5 \%$ \\
\hline 5 & Canadá & 3.917 .107 .684 & $4,7 \%$ & $84,4 \%$ \\
\hline 6 & Japão & 3.343 .413 .253 & $4,0 \%$ & $41,0 \%$ \\
\hline 7 & Bélgica & 2.345 .515 .905 & $2,8 \%$ & $53,9 \%$ \\
\hline 8 & Espanha & 1.986 .936 .089 & $2,4 \%$ & $171,3 \%$ \\
\hline 9 & Holanda & 1.901 .081 .104 & $2,3 \%$ & $36,3 \%$ \\
\hline 10 & Suiça & 1.802 .948 .441 & $2,1 \%$ & $59,2 \%$ \\
\hline 11 & Itália & 1.635 .333 .570 & $1,9 \%$ & $122,0 \%$ \\
\hline 12 & Áustria & 1.447 .368 .632 & $1,7 \%$ & $23,0 \%$ \\
\hline 13 & Suécia & 1.376.217.617 & $1,6 \%$ & $88,5 \%$ \\
\hline 14 & Austrália & 1.147 .282 .524 & $1,4 \%$ & $191,8 \%$ \\
\hline 15 & China & 1.140 .812 .737 & $1,4 \%$ & $4,7 \%$ \\
\hline 16 & México & 1.111 .179 .236 & $1,3 \%$ & $14,6 \%$ \\
\hline 17 & Noruega & 1.056 .447 .299 & $1,3 \%$ & $89,3 \%$ \\
\hline 18 & República da Coréia & 1.034 .066 .983 & $1,2 \%$ & $372,7 \%$ \\
\hline 19 & Dinamarca & 945.802 .478 & $1,1 \%$ & $82,9 \%$ \\
\hline 20 & República Tcheca & 814.749 .436 & $1,0 \%$ & $177,3 \%$ \\
\hline & Total da Amostra & 73.068 .826 .556 & $86,7 \%$ & $75,1 \%$ \\
\hline 47 & Brasil & 114.639.261 & $0,1 \%$ & $34,3 \%$ \\
\hline 137 & Total Geral & 84.236 .971 .808 & $100,0 \%$ & $81,8 \%$ \\
\hline
\end{tabular}

Fonte: COMTRADE/ONU; elaboração DECOMTEC/FIESP.

* Dados dos produtos "móveis" classificados nas seguintes nomenclaturas do Mercosul: 940140, 940150 , 940161, 940169, 940180, 940190, 940330, 940340, 940350, 940360, 940370, 940380, 940390. 


\section{Anexo 3}

Principais países de destino de Exportação dos móveis brasileiros em US\$ em 2007 - Crescimento das Exportações de 2001 a 2007*

\begin{tabular}{|c|c|c|c|c|c|}
\hline & $\begin{array}{c}\text { Destinos das } \\
\text { Exportações de } \\
\text { Móveis Brasileiros }\end{array}$ & 2006 (US\$) & 2007 (US\$) & $\begin{array}{l}\text { Participação } \\
2007 \text { em \% }\end{array}$ & $\begin{array}{c}\% \text { Crescimento } \\
\text { de } 2001 / 07\end{array}$ \\
\hline 1 & ESTADOS UNIDOS & 264.912 .253 & 218.295 .600 & 25,11 & 72,3 \\
\hline 2 & FRANCA & 81.379 .732 & 80.553 .690 & 9,27 & 30,4 \\
\hline 3 & REINO UNIDO & 85.086 .058 & 76.961 .355 & 8,85 & 100,6 \\
\hline 4 & ARGENTINA & 68.653 .287 & 72.146 .021 & 8,30 & 24,1 \\
\hline 5 & ESPANHA & 36.099 .385 & 52.176 .669 & 6,00 & $1.389,1$ \\
\hline 6 & ALEMANHA & 28.067 .623 & 36.140 .518 & 4,16 & 64,6 \\
\hline 7 & CHILE & 32.769 .902 & 34.072 .183 & 3,92 & 498,2 \\
\hline 8 & ANGOLA & 23.873 .088 & 30.249 .734 & 3,48 & $3.553,8$ \\
\hline 9 & HOLANDA & 23.131 .334 & 28.279 .884 & 3,25 & 27,9 \\
\hline 10 & URUGUAI & 12.223 .104 & 15.237 .636 & 1,75 & $(13,0)$ \\
\hline 11 & VENEZUELA & 10.740 .117 & 15.054 .045 & 1,73 & 187,5 \\
\hline 12 & MEXICO & 14.672 .637 & 14.919 .165 & 1,72 & 408,0 \\
\hline 13 & IRLANDA & 16.950 .229 & 14.361 .817 & 1,65 & 88,7 \\
\hline 14 & CANADA & 16.558 .332 & 13.764 .902 & 1,58 & 458,0 \\
\hline 15 & PORTO RICO & 12.985 .005 & 13.441 .595 & 1,55 & 62,1 \\
\hline 16 & PORTUGAL & 6.280 .310 & 9.219 .174 & 1,06 & 496,8 \\
\hline 17 & BELGICA & 6.580 .466 & 7.824 .760 & 0,90 & 184,6 \\
\hline 18 & PARAGUAI & 4.972 .311 & 7.627 .647 & 0,88 & 155,1 \\
\hline 19 & PERU & 4.347 .822 & 7.151 .698 & 0,82 & $1.280,1$ \\
\hline \multirow[t]{3}{*}{20} & PANAMA & 5.820 .851 & 6.593 .728 & 0,76 & 58,5 \\
\hline & Total da Amostra & 756.103 .846 & 754.071 .821 & 86,74 & 90,8 \\
\hline & TOTAL GERAL & 912.389 .063 & 869.334 .505 & 100,00 & 107,0 \\
\hline
\end{tabular}

Fonte: ALICEWEB/MDIC; elaboração DECOMTEC/FIESP.

* Dados dos produtos “móveis" classificados nas seguintes nomenclaturas do Mercosul: 940140, 940150, 940161, 940169, 940180, 940190, 940330, 940340, 940350, 940360, 940370, 940380, 940390. 


\section{Anexo 4}

\section{Consumo Aparente de Móveis no Brasil (em R\$) em 2006}

Composição do Consumo Aparente - 2006 (Em Bilhöes R\$)

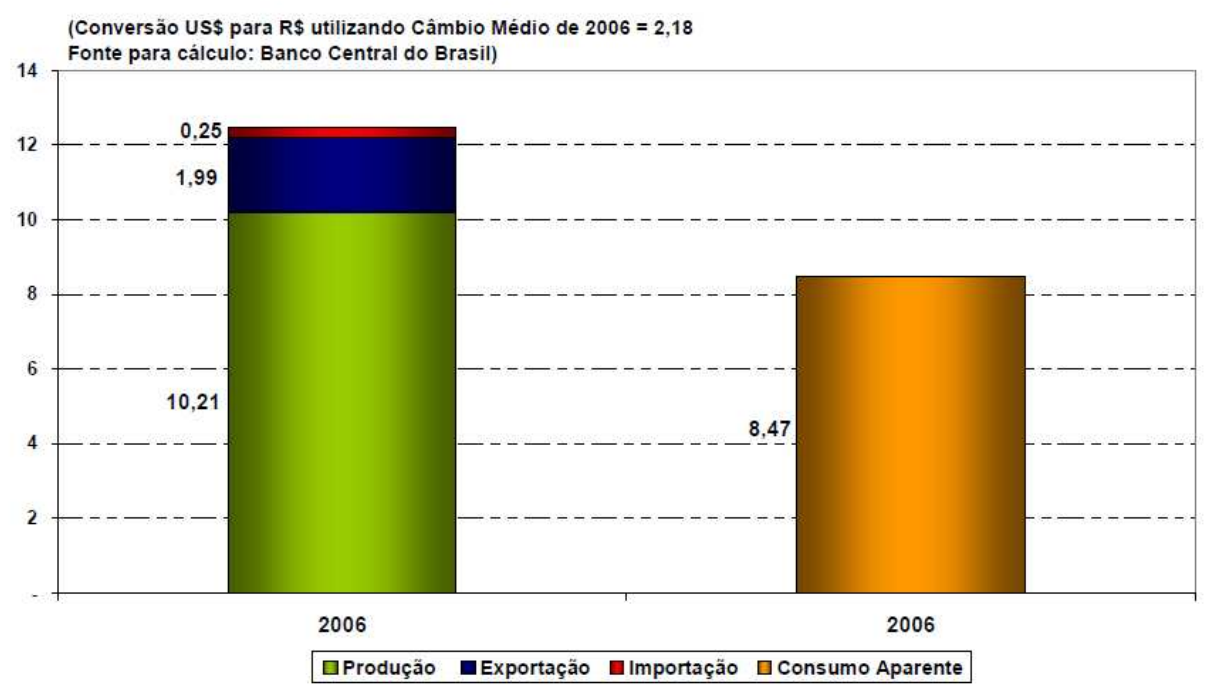

Fonte: Ministério do Desenvolvimento, Indústria e Comérico; elaboração FIESP

\section{Anexo 5 \\ Evolução do Mercado Brasileiro de Móveis}

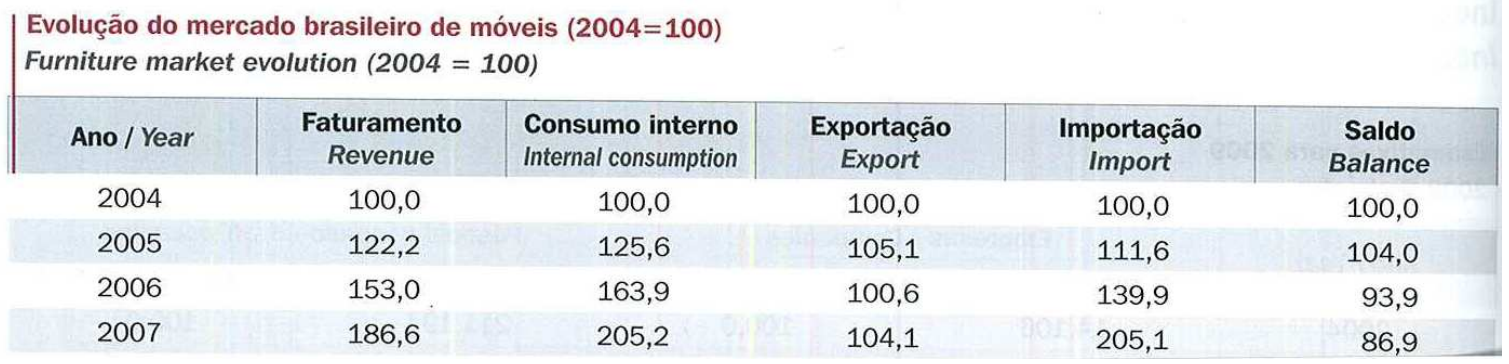

Fonte: Secex/IEMI 
Anexo 6

Evolução do percentual de crescimento do faturamento entre os anos de 2001 e 2007 da empresa Móveis RA

\begin{tabular}{|c|c|}
\hline Períodos analisados & Variação percentual encontrada \\
\hline 2001 a 2002 & 19,22 \\
\hline 2002 a 2003 & 18,77 \\
\hline 2003 a 2004 & $-5,03$ \\
\hline 2004 a 2005 & 15,10 \\
\hline 2005 a 2006 & $-21,13$ \\
\hline 2006 a 2007 & $-8,79$ \\
\hline
\end{tabular}

Fonte: documentos da empresa

\section{Anexo 7}

Taxas cambiais mensais (Real x Dólar), praticadas nas vendas da empresa no período de 2002 a 2007

\begin{tabular}{|c|c|c|c|c|c|c|}
\hline Meses & $\mathbf{2 . 0 0 2}$ & $\mathbf{2 . 0 0 3}$ & $\mathbf{2 . 0 0 4}$ & $\mathbf{2 . 0 0 5}$ & $\mathbf{2 . 0 0 6}$ & $\mathbf{2 . 0 0 7}$ \\
\hline Janeiro & 2,30 & 3,40 & 2,86 & 2,69 & 2,28 & 2,13 \\
\hline Fevereiro & 2,42 & 3,58 & 2,93 & 2,57 & 2,15 & 2,09 \\
\hline Março & 2,30 & 3,61 & 2,90 & 2,7 & 2,16 & 2,09 \\
\hline Abril & 2,34 & 3,15 & 2,90 & 2,58 & 2,13 & 2,03 \\
\hline Maio & 2,46 & 2,94 & 2,99 & 2,45 & 2,21 & 1,97 \\
\hline Junho & 2,68 & 2,88 & 3,12 & 2,41 & 2,24 & 1,93 \\
\hline Julho & 2,89 & 2,86 & 3,05 & 2,37 & 2,18 & 1,87 \\
\hline Agosto & 3,01 & 2,98 & 3,01 & 2,36 & 2,16 & 1,95 \\
\hline Setembro & 3,32 & 2,89 & 2,89 & 2,29 & 2,17 & 1,90 \\
\hline Outubro & 3,82 & 2,86 & 2,85 & 2,25 & 2,13 & 1,80 \\
\hline Novembro & 3,45 & 2,91 & 2,79 & 2,20 & 2,16 & 1,75 \\
\hline Dezembro & 3,77 & 2,92 & 2,72 & 2,26 & 2,14 & 1,79 \\
\hline
\end{tabular}

Fonte: documentsos da empresa 


\section{Anexo 8}

Gráfico elaborado pelo Sr. Omar e pelo Sr. Epitáfio, demonstrando claramente a queda de faturamento com o passar dos últimos dois anos. No eixo vertical temos a taxa de câmbio em reais por dólar, no eixo horizontal os meses do ano.

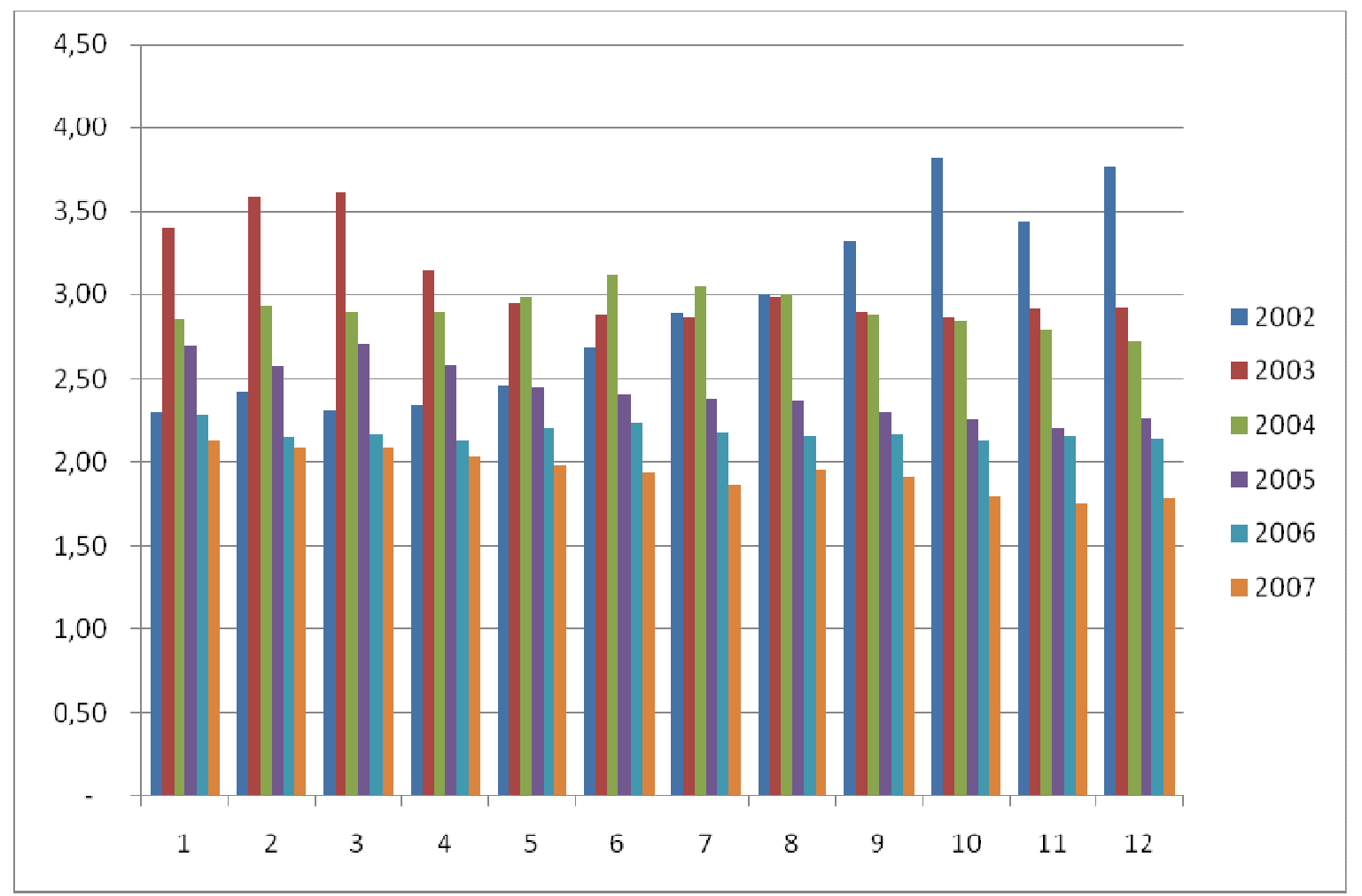

